\title{
HEART BLOCK WITH ANEURYSM OF THE AORTIC SINUS
}

\author{
BY \\ PAUL F. DURAS \\ From St. Andrew's Hospital, Northampton \\ Received August 18, 1943
}

Disturbances of conduction in the heart may be purely functional, when for example demands are made on the conduction path very early in diastole as seen in blocked and aberrantly conducted auricular extrasystoles (Scherf and Boyd, 1940), or when too many stimuli are presented for conduction within a short time as with the incomplete A-V block that always exists in auricular fibrillation. Conduction disturbances may also be due to vagal inhibition. They may occur transiently after pneumonia and influenza, and are well known in diphtheria; recently Neubauer (1942) found many examples of partial and complete block in 100 cases of diphtheria. Over-digitalization may through poisoning of the A-V node lead to prolongation of conduction time, partial, or complete block. A permanent block can be established through coronary sclerosis, coronary thrombosis, rheumatic heart disease, syphilitic gumma, and more rarely through diphtheria, tuberculosis, and carcinoma affecting the A-V node or bundle directly. Congenital complete heart block is also known, and a few cases were found by Yater (1929), Aitken (1932), Campbell and Suzman (1934), and Currie (1940). The exceptional event of heart block as a result of direct trauma to the chest wall is described by Coffen (1930), Walker (1933), and White (1937).

The following is the report of a case in which complete heart block was associated with an intracardiac aneurysm and aortic stenosis.

A farm labourer, 49 years of age, was admitted to the General Hospital, Northampton, on September 16, 1942. He had been off work since the beginning of July 1942, because of tiredness, dizziness, loss of weight, pains "all over the body," pain and frequency of micturition, and on one or two occasions attacks of hæmaturia. Mainly because of the urinary symptoms he was sent to hospital. Twenty years ago he had diphtheria, but had always enjoyed fairly good health otherwise, except for a regular winter cough. His father and one sister had died of tuberculosis. He was married and had three children aged 1, 7, and 10 years, who were all well; there had been one miscarriage and one stillbirth.

On admission he complained of the above-mentioned symptoms, but his appetite was good and there was no cough, breathlessness, headache, vomiting, abdominal pain, or swelling of the ankles. He was pale and rather thin, but well built. Temp. 99 , resp. rate 20 , pulse rate 36 . There was marked clubbing of the fingers and toes. The cardiac impulse was felt in the fifth intercostal space, one inch outside the mid-clavicular line, and was of a heaving character. A thrill could be felt in the aortic area where there was a loud and rough systolic murmur, which was propagated to the neck and towards the right axilla; a systolic murmur was also audible in the mitral region traceable towards the left axillary line. The blood pressure was 100/75 on the right side, and 120/60 on the left. The pulse was markedly anacrotic and of fair volume in the right arm, while in the left it was of a better volume but not anacrotic. The neck veins were not engorged and showed no abnormal pulsation. The liver was not enlarged; the spleen and kidneys were not palpable. Nothing abnormal could be found in the lungs. There was some slight tenderness in the suprapubic region. The urinary symptoms were proved to be due to subacute cystitis, which cleared up within a fortnight. A radiograph of the chest showed the heart enlarged to the left with rounding of the apex, no broadening of the aortic shadow, and clear lungfields. Fig. 1 taken on September 22 shows a lævocardiogram with regular auricular and regular ventricular activity but continuous variation in the length of the $P-R$ interval. The 


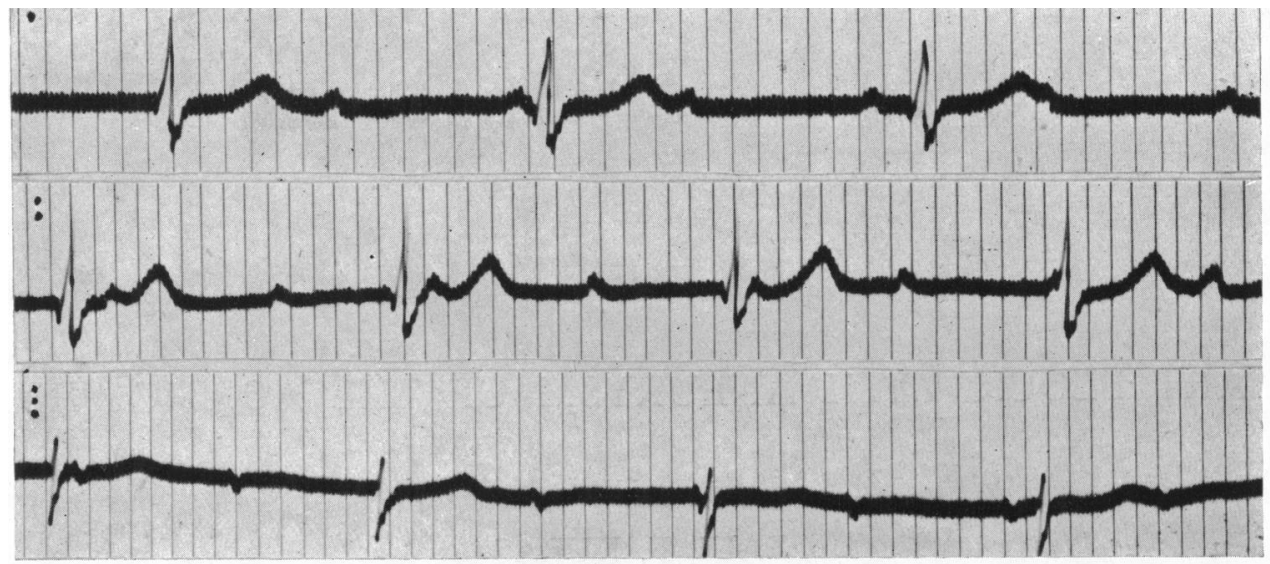

FIG. 1.-Complete heart block and left axis deviation. Auricular rate, 86; ventricular, 40 a minute.

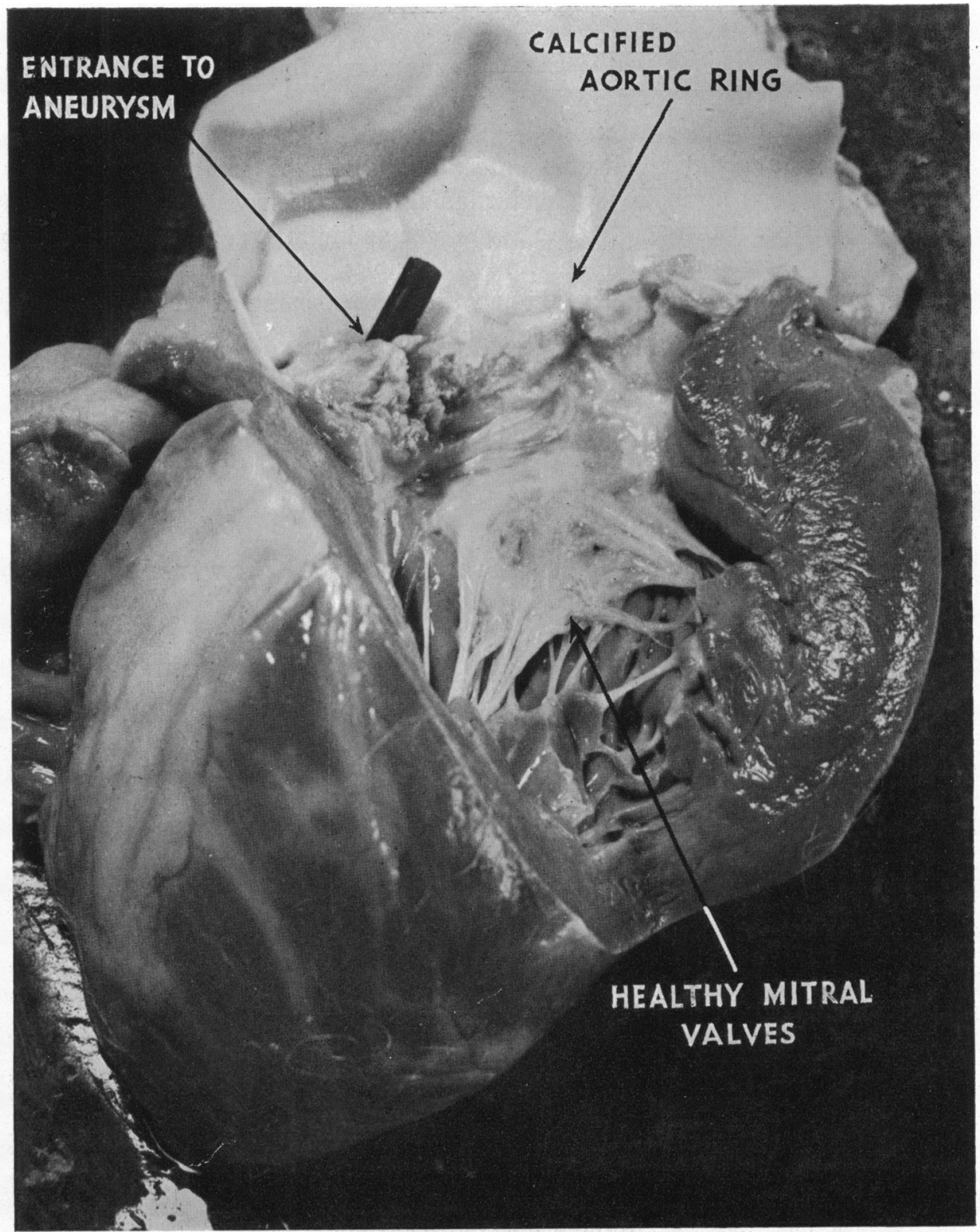

Fig. 2.-View of the heart opened from the front. A rod is placed into the entrance to the aneurysm behind the right posterior aortic valve. The whole aortic ring is severely calcified; the aorta itself and the mitral valve are unaffected. 
auricles contract at a rate of 86 , the ventricles at a rate of 40 beats a minute. The width and shape of the ventricular complexes (broadened to $0.12 \mathrm{sec}$. and slightly slurred) cannot be evaluated as indicating a myocardial lesion; the excitation spreads abnormally within the ventricles due to the fact that deep, abnormally located centres have assumed control. There is no displacement of the S-T segment, and the $\mathrm{T}$ waves are upright in all leads. The Wasserman reaction was negative.

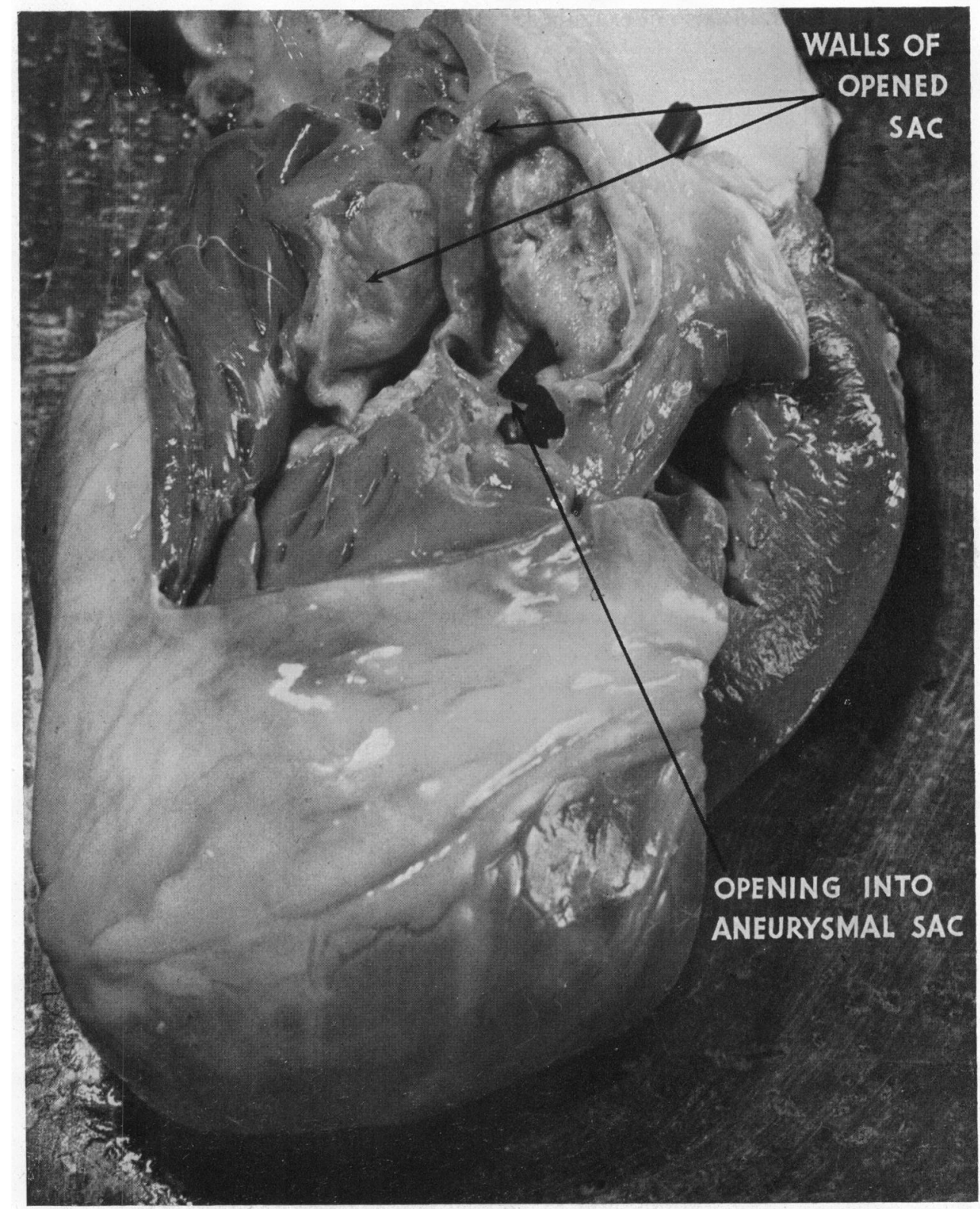

FIG. 3.-View of the right auricle, and of the aneurysm, the walls of which have been cut open and the two halves folded back. The rod appears in the lower part of the aneurysm and shows the communication with the aorta. The two upper arrows point to the two halves of the aneurysm.

Aortic stenosis and complete heart block was diagnosed, and a tentative diagnosis of an aortic aneurysm was considered. The patient was about to be discharged from the hospital on October 1, 1942, when it was noted on the evening of the day before that his temperature was $99 \cdot 2$; the next day it had risen to 100 and remained there until October 5 ; no cause could be found for the temperature, and the patient felt well and had no complaints. On the morning of October 6 he woke up at 5.30 a.m. feeling clammy and faint, and found it difficult to get 
his breath. He was examined ten minutes later. The pulse was of a good volume and regular, but the rate had dropped to 22 . He was not cyanosed, but was grey in colour, cold and clammy and very dyspnœic. He improved on coramine and brandy, but threequarters of an hour later he died suddenly, presumably due to more profound slowing of the ventricular rate with ultimate standstill.

At necropsy the brain was not examined. The lungs were voluminous, but not congested; they appeared to be normal, apart from a healed apical lesion on the left side. The pleural cavities were normal. The pericardium contained some clear fluid. The heart was hypertrophied, mainly in the left ventricle, and the right auricle was dilated. The tricuspid, mitral, and pulmonary valves were normal. A saccular aneurysm of about $11 / 2$ inch diameter was found projecting into the right auricle, lying on the lower part of the interauricular septum and communicating with the aorta through a $1 / 4$ inch diameter passage immediately above the right posterior aortic valve. There was severe calcification of the aortic valve ring which was continuous with the wall of the aneurysmal sac (Fig. 2 and 3). The aneurysm was not ruptured. The aorta and blood vessels, including the coronary arteries, showed no atheroma. The liver and spleen were slightly enlarged and showed early venous congestion. The gastrointestinal tract and the pancreas were normal.

\section{Discussion}

The ascending part of the aorta is normally a little enlarged just above its origin; this enlargement consists of three small pouches, known as the sinuses of Valsalva, opposite to which are attached the three semilunar valves. Aneurysm may develop here and involve one, two, or all three of these sinuses of the aorta. They rarely attain a size to produce physical signs, and before symptoms appear can lead to sudden death, which may be of medico-legal interest. Death occurs through perforation, either into the pericardium or more rarely into the superior vena cava, pulmonary artery, or right or left auricle. Syphilitic aortitis is usually the cause but a few cases were found with ordinary atheromatous changes. The aortic valves are as a rule affected. Whilst I am not acquainted with a publication of a case similar to the above described, I found a reference to the aneurysm of the sinus of the aorta by Matthes (1928) who states that it is a very rare occurrence, that it affects usually the right sinus, and that it may develop into the right ventricle, more rarely into the right auricle, or outwards and upwards. He further mentions that these aneurysm can be diagnosed only if they burst, and thus lead to a conspicuous alteration of the whole clinical picture, e.g. the sudden occurrence of a very loud murmur which extends over both heart phases, and was not present previously. In any case one can only make the diagnosis if one knows that the aortic valves are diseased.

Reference should also be made to the case of Micks (1940) who found aneurysms of all three sinuses of Valsava; the patient developed complete heart block before his death.

In trying to find the cause of the heart block it appears that four possibilities have to be considered.

1. The absence of any fainting attacks may suggest that the block was congenital. The patient was carefully interrogated as to any previous loss of consciousness, etc., but denied firmly any such occurrence. On the other hand, he volunteered the information that his fingers were clubbed as long as he could remember. However, the postulates of Yater (1929), concerning congenital heart block, are not completely fulfilled, and in view of the other findings this possibility is not very likely.

2. He had diphtheria twenty years ago. There is as yet no conclusive evidence as to the after-effects of diphtheria on the heart. In 100 cases which had suffered from diphtheria 5 to 10 years previously Jones and White (1927) did not find any signs of heart disease. Hoskins (1926), on the other hand, found persistent cardiographic changes quite common after diph- 
theria, and Butler and Levine (1929) found a history of diphtheria in 10 out of 20 patients with heart block of obscure origin, and believe that diphtheria is of ætiological significance in many such cases.

3. The aortic valve ring was severely calcified, causing aortic stenosis. Auricular-ventricular or bundle branch block is an occasional complication of aortic stenosis; this may be due to extension of the calcifying process from the aortic ring into the interventricular septum with implication of the bundle of His. Unfortunately a histological examination of the bundle was not made in this case.

4. The aneurysmal sac was situated close to the auricular part of the Aschoff-Tawara node, and it is most likely that the pressure of the aneurysm on the node caused the block. On this assumption the post-mortem report as to the cause of death was as follows : Aneurysmal sac of aorta, pressing on bundle of His, secondary to ulcerative changes in the aortic valve ring.

\section{SUMMARY}

A case is reported with an aneurysm of a sinus of Valsalva and complete heart block. The possible causes of the block are discussed, and the conclusion is drawn that the block was due to pressure of the aneurysm on the conducting path.

My thanks are due to Dr. W. M. Robson for permission to report the case, and to Dr. Margaret Masson for the photographs (Fig. 2 and 3 ) and most helpful co-operation.

\section{REFERENCES}

Aitken, Janet (1932), Lancet, 2, 1375.

Butler and Levine, S. A. (1929). Amer. Heart J., 5, 592.

Campbell, M. and Suzman, S. (1934). Ibid., 9, 304.

Coffen, T. H. (1930). Ibid., 5, 667.

Currie, G. M. (1940). Brit. med. J., 1, 769.

Hoskin, J. (1926). Lancet, 1, 1141.

Jones, T. D. and White, P. D. (1927). Amer. Heart J., 3, 190.

Matthes, M. (1928). Lehrbuch der Differentialdiagnose Innerer Krankheiten, Berlin.

Micks, R. H. (1940). Brit. Heart J., 2, 63.

Neubauer, C. (1942). Brit. med. J., $2,91$.

Scherf, D. and Boyd, L. J. Clinical Electrocardiography, London.

Walker, G. F. (1933). The Injured Workman, Bristol.

White, P. D. (1937). Heart Disease, New York.

Yater, W. M. (1929). Amer. J. Dis. Child., 38, 112. 